\title{
Chemical Compositions, Antioxidant and Antimicrobial Activities of the Essential Oil and Extracts of Lamiaceae Family (Ocimum basilicum and Thymbra spicata) from Turkey
}

\author{
Omer ERTURK ${ }^{1}$, Guler Inci TANRIKULU ${ }^{* 2}$, Ceren YAVUZ ${ }^{3}$, Zehra CAN ${ }^{4}$, Hilal Ebru \\ CAKIR $^{5}$
}

\author{
${ }^{1}$ Department of Biology, Faculty of Arts and Sciences, Ordu University, Ordu, Turkey \\ ${ }^{2}$ Department of Chemistry, Faculty of Arts and Sciences, Amasya University, Amasya, Turkey \\ ${ }^{3}$ Department of Biology, Faculty of Arts and Sciences, Amasya University, Amasya, Turkey \\ ${ }^{4}$ Sebinkarahisar Technical Sciences Vocational School, Giresun University, Giresun, Turkey \\ ${ }^{5}$ Department of Chemistry, Faculty of Science, Karadeniz Technical University, Trabzon, Turkey
}

Received: 03 May 2017 - Revised: 11 July 2017 - Accepted: 01 September 2017

\begin{abstract}
Lamiaceae has numerous proven biological properties. Our aim was to investigate the antioxidant and antimicrobial activities and chemical composition of essential oil and extracts of Ocimum basilicum and Thymbra spicata. For this purpose, we used four Gram-positive (Staphylococcus aureus, Streptomyces murinus, Micrococcus luteus, Bacillus subtilis), four Gram-negative (Klebsiella pneumoniae, Pseudomonas aeruginosa, Yersina enterocolitica, Proteus vulgaris), a yeast (Candida albicans) and a mold (Aspergilus niger). Essential oil and the extracts of Thymbra spicata have the most effective and significant activity against the bacteria, yeast and mold. Antioxidant activity of the Thymbra spicata was higher than Ocimum basilicum. Phenolic compounds have good properties like antioxidants acting as reducing agent, hydrogen donors and singlet oxygen quenchers. Fourteen phenolic compounds were analyzed and some phenolics were detected in Ocimum basilicum and Thymbra spicata. These results suggest that Lamiaceae is rich in phenolic compounds and has antimicrobial and antioxidant properties as well. Therefore, it can be a useful herbal source in food and drug industries.
\end{abstract}

Keywords: Lamiaceae, Antimicrobial and Antioxidant Activities, GC-MS, HPLC.

\section{INTRODUCTION}

Medicinal plants, since times immemorial, have been used in virtually all cultures as a source of medicine. The use of traditional medicine and medicinal plants in most developing countries has been widely observed as a normative basis for the maintenance of good health. The relationship between plants and people has been discussed for years, and it will be discussed in the future. Infectious diseases account for approximately one-half of all deaths in the tropical regions of the world and at least developed countries. In industrialized and advanced nations, despite the progress made in the understanding of microbiology and their control, incidents of epidemics due to drug-resistant microorganisms and the emergence of up to the present unknown disease-causing microbes, pose enormous public health concerns. Today it is conjecturable that plant materials are available or have ensured the models for $50 \%$ Western

\footnotetext{
*Corresponding Author E-mail: inci.emiroglu@amasya.edu.tr
} 
drugs [1]. Many commercially certified drugs used in modern medicine were primarily used in a raw untreated form in conventional or folk healing practices or for another objective that proposed potentially useful biological activity [2]. The primary benefits of using plant-derived medicines are relatively safer than synthetic alternatives, offering profound therapeutic benefits and more affordable treatment [2]. The extracts and essential oils of many plants/herbs have been shown to exert biological activity in vitro and in vivo, which justified research on traditional medicine focused on the characterisation of antimicrobial activity of these plants [3].

Common basil (Ocimum basilicum L.; O. basilicum), a member of the Lamiaceae family is an annual herb which is known locally as "fesleğen or reyhan", is native to Asia and is widely grown as an ornamental or field crops from seed in the Mediterranean countries including Turkey [4,5]. Basil is used in pharmacy for diuretic and stimulating properties, in perfumes and cosmetics for its smell; in fact, it is a part of many fragrance compositions [6]. Its oil has been found to be beneficial for the alleviation of mental fatigue, colds, spasms, rhinitis, and as a first aid treatment for wasp stings and snake bites. The essential oil has antioxidant, physicochemical and insect-repelling anticonvulsant, hypnotic, and antioxidant activities [7-9]. Various researchers have reported chemical composition of the essential oil of $O$. basilicum $[8,9]$. They are regarded as oil-rich on the basis of their essential oil contents. The genus Thymbra, which belongs to Lamiaceae family, includes many native plants of the Mediterranean region in Turkey and is locally known as Karabaş kekik, Kara kekik, Sater or Zater [9-11]. It is traditionally used for flavouring different kinds of food products, as herbal tea and in folk medicine as an antiseptic agent [11,12]. The leafy part of plants such as sage, thyme, oregano and savoury belonging to the Lamiaceae family have been added to meat, fish and food products for years. In addition to improving flavour, certain spices and essential oils prolong the storage life of foods by increasing an antimicrobial activity [13]. The flora of Turkey has two species of Thymbra and it attracted a great deal of research interest due to their potential as a source of natural antioxidants and biologically active compounds [14].

In the present study, different groups of microorganisms were used to evaluate the antimicrobial activity of Lamiaceae and chemical composition of the essential oil and extracted from Lamiaceae and its biological properties were investigated. The antimicrobial activity was tested by using agar disc diffusion and broth microdilution methods. Determination of antioxidant activity was tested by using Total Phenolic Contents (TPC), Total Flavonoid Contents (TFC) and Condensed Tannin (CT) and ferric reducing antioxidant power (RFAP). Fourteen different phenolic compounds were determined using reverse phase- high performance liquid chromatography (RP-HPLC). The chemical composition was tested by using GC-MS.

\section{EXPERIMENTAL METHOD}

\subsection{Plant material}

Samples of Ocimum basilicum and Tyhmbra spicata were purchased commercially in Amasya, Turkey and dried at room temperature.

\subsection{Preparation of extracts for antimicrobial activity}

Extraction method described elsewhere was used for the antimicrobial screening with slight modification [15]. The plants (90 g) separated into equal three parts. The first parts $(30 \mathrm{~g})$ were refluxed with $250 \mathrm{~mL}$ ethanol, the second parts $(30 \mathrm{~g})$ were refluxed with $250 \mathrm{~mL}$ dichloromethane and the third parts $(30 \mathrm{~g})$ were refluxed with $250 \mathrm{~mL}$-hexane for $2 \mathrm{~h}$. The infusions were filtered and the solvents were removed under rotary vacuum. Then the residue dissolved in DMSO. Oil and extracts samples were stored at $4^{\circ} \mathrm{C}$ in sealed glass vials. 


\subsection{Preparation of essential oils}

The essential oils of the plants were produced by the Clevenger hydrodistillation method [16]. Plant materials $(50 \mathrm{~g})$ cut into small pieces and placed in a distillation apparatus with double distilled water and hydrodistilled for $3 \mathrm{~h}$. They were stored at $4^{\circ} \mathrm{C}$ until tested.

\subsection{Test organisms and growth conditions}

Essential oil and extracts of Lamiaceae family were tested against a panel of microorganisms, including Staphylococcus aureus (S. aureus) ATCC 25923, Pseudomonas aeruginosa ( $P$. aeruginosa) ATCC 27853, Yersinia enterocolitica ( $Y$. enterocolitica) ATCC 27729, Klebsiella pneumonia (K. pneumonia) ATCC 13883, Micrococcus luteus (M. luteus) B1018, Bacillus subtilis (B. subtilis) ATCC 6633, Proteus vulgaris (P. vulgaris) ATCC 13315, Streptomyces murinus (S. murinus) ISP 5091, Candida albicans (C. albicans) ATCC 10231, Aspergillus niger (A. niger) ATCC 9642. Bacterial strains were cultured overnight at $37^{\circ} \mathrm{C}$ in Mueller Hinton agar (MHA). Yeast and mold were cultured overnight at $35^{\circ} \mathrm{C}$ in Sabouraud dextrose agar. Moreover, bacteria species were grown in Mueller Hinton Agar (Merck) and Mueller Hinton Broth (Merck). C. albicans and A. niger were grown in Sabouraud Dextrose Broth (Difco) and Sabouraud Dextrose Agar (Oxoid). The concentration of bacterial suspensions was adjusted to $\sim 10^{8}$ cells $/ \mathrm{mL}$ and fungal suspension to $\sim 10^{7}$ cells $/ \mathrm{mL}$.

\subsection{Antimicrobial assays}

The disc diffusion method was employed for the determination of antimicrobial activities and microdilution method of the essential oil and extracts.

\subsection{Screening for antimicrobial activities}

Antimicrobial activity was measured with diffusion disk plates on agar. In order to test antimicrobial and antioxidant activity, the fractions of $O$. basilicum and $T$. spicata samples were dissolved in $70 \%$ ethanol. Suspensions $(50 \mu \mathrm{L})$ with approximately $10^{8}$ bacteria and fungus per millilitre were placed in Petri dishes, over agar and dispersed. Inhibition zones were determined after incubation at $25^{\circ} \mathrm{C}$ for $24 \mathrm{~h}[8,17]$. For the bacteria ampicillin and cephazolin obtained from a local pharmacy were used as a positive control and alcohol as a negative control.

\subsection{Determination of minimum inhibitory concentration (mic) with microdilution assay}

The agar dilution method, described by Vanden et al in 1991 was used for the antimicrobial screening with slight modifications. Instead of 96 well microtitre plates, 24 well tissue culture (Corning) plates were used. The crude extracts were dissolved in $70 \%$ ethanol and physiological Tris buffer (Amresco 0826-500G) mixture (1:4) and mixed with an equal amount of 3\% agar solution Sabouraud Dextrose Agar (Oxoid) for fungus at $25^{\circ} \mathrm{C}$ and Mueller Hinton Agar (Merck) for bacteria at $37^{\circ} \mathrm{C}$. Each of the crude extract samples was tested at concentrations of 50, 25, 12.5, and $6.25 \mathrm{mg} / \mathrm{mL}$. From the test solutions, $400 \mu \mathrm{L}$ was transferred into each well of the tissue culture plate. After solubilization, each well was inoculated with 10 $\mu \mathrm{L}$ of freshly prepared bacterial suspension of $10^{8}$ bacteria, $10^{7}$ fungi $/ \mathrm{mL}$ and incubated at $37^{\circ} \mathrm{C}$ for $24 \mathrm{~h}$. The bacterial and fungal growth was assessed by a stereo microscope after the incubation period [18].

\subsection{Preparation of the extracts for chemical composition and antioxidant capacity}

For extraction, approximately $3 \mathrm{~g}$ of dry plant samples were placed into a falcon tube with $50 \mathrm{~mL}$ of absolute methanol. The mixture was stirred continuously on a shaker (Heidolph Promax 2020, Schwabach, Germany) at room temperature during 24 hours. Particles were removed using filter paper. The final volume of the solution was adjusted by the addition of methanol. 


\subsection{Determination of antioxidant capacity}

The polyphenolic contents of the methanolic samples were evaluated in four different ways; Total Phenolic Contents (TPC), Total Flavonoid Contents (TFC), Condensed Tannin (CT) and ferric reducing antioxidant power (FRAP). Total phenolic compounds were determined by an end-point assay of Folin-Ciocalteu method [19]. First, $680 \mu \mathrm{L}$ distilled water, $400 \mu \mathrm{L} 0.5 \mathrm{~N}$ Folin-Ciocalteu reagent and $20 \mu \mathrm{L}$ methanolic sample extract were mixed in a test tube and well vortexed. Next, $400 \mu \mathrm{L} \mathrm{Na}_{2} \mathrm{CO}_{3}(10 \%)$ was added and well vortexed after incubated for $2 \mathrm{~h}$ in the dark at room temperature. After the incubation the absorbance was measured at $760 \mathrm{~nm}$, the results were calculated using a standard graph as mg of Gallic Acid Equivalent (GAE) per 100 grams of sample.

The total flavonoid contents of the samples were measured using a spectrophotometric method as reported elsewhere [20]. Briefly, $500 \mu \mathrm{L}$ methanolic samples, $4.3 \mathrm{~mL}$ methanol 100 $\mu \mathrm{L}$ of $10 \% \mathrm{Al}\left(\mathrm{NO}_{3}\right)_{3}$ and $100 \mu \mathrm{L}$ of $1 \mathrm{M} \mathrm{NH}_{4} \cdot \mathrm{CH}_{3} \mathrm{COO}$ were added to a test tube and incubated at room temperature for 40-min periods, the absorbance was measured against a blank at 415 $\mathrm{nm}$. A standard calibration curve was plotted using quercetin. The total flavonoid concentration was expressed as mg of Quercetin Equivalent (QE) per 100 grams of sample.

Condensed tannins were determined according to the method by Julkunen-Titto [21]. For each, $25 \mu \mathrm{L}$ of various concentrations of plant extract was mixed with $750 \mu \mathrm{L}$ of $4 \%$ vanillin in methanol, to which $375 \mu \mathrm{L}$ of concentrated $\mathrm{HCl}$ was added. The well-mixed solution was incubated in the dark at room temperature for 20 minutes. The absorbance against a blank was then measured at $500 \mathrm{~nm}$. (+)- Catechin was used to make the standard curve $(0.05-1 \mathrm{mg} / \mathrm{mL})$. The results were expressed as mg Catechin Equivalent (CE) per 100 grams of sample.

Ferric tripyridyltriazine (Fe-III-TPTZ) complex was used to determine total antioxidant capacity [22]. Briefly, working FRAP reagent was prepared as required by mixing $25 \mathrm{~mL}$ of $300 \mathrm{mM}$ acetate buffer, $\mathrm{pH} 3.6$, with $2.5 \mathrm{~mL}$ of $10 \mathrm{mM}$ TPTZ solution in $40 \mathrm{mM} \mathrm{HCl}$ and 2.5 $\mathrm{mL}$ of $20 \mathrm{mM} \mathrm{FeCl}_{3} .6 \mathrm{H}_{2} \mathrm{O}$ solution. Next, $3 \mathrm{~mL}$ freshly prepared FRAP reagent and $100 \mu \mathrm{L}$ of extract were mixed and incubated for $4 \mathrm{~min}$ at $37^{\circ} \mathrm{C}$, and the absorbance was measured at 595 $\mathrm{nm}$ against a reagent blank containing distilled water. Trolox was used as positive control to construct a reference curve $(62.5-1000 \mu \mathrm{M})$. FRAP values were expressed as mM Trolox equivalent of 100 grams sample.

\subsection{Analysis of phenolic compounds by RP-HPLC}

Fourteen standards of phenolic compounds were analyzed using HPLC (Elite LaChrom Hitachi, Japan). The sample was injected into the HPLC system, set up with a reverse phase C18 column ( $150 \mathrm{~mm} \times 4.6 \mathrm{~mm}, 5 \mu \mathrm{m}$; Fortis). Acetonitrile, water and acetic acid were used for the mobile phase by applying a programmed gradient. The mobile phase consisted of (A) $2 \%$ acetic acid in water and (B) acetonitrile: water (70: 30). The samples injection volume was 20 $\mu \mathrm{L}$, column temperature was $30^{\circ} \mathrm{C}$ and flow rate was $0.75 \mathrm{~mL} / \mathrm{min}$. The programmed solvent used began with a linear gradient held at $95 \%$ for three minutes, decreasing to $80 \% \mathrm{~A}$ at $10 \mathrm{~min}$, $60 \% \mathrm{~A}$ at $20 \mathrm{~min}, 20 \% \mathrm{~A}$ at $30 \mathrm{~min}$ and finally $95 \% \mathrm{~A}$ at $50 \mathrm{~min}$ as described elsewhere [23].

\section{RESULTS and DISCUSSIONS}

\subsection{Antimicrobial activities}

Results of disc diffusion methods were summarized in Table 1-2. Essential oil and extracts of the plants displayed varying degrees of activity against bacteria strains. Essential oil of $O$. basilicum (F00) was also effective on A. niger, S. murinus, P. vulgaris. Antimicrobial activity of F00 against the $K$. pneumonia, S. aureus, M. luteus, C. albicans, B. subtilis and $P$. aureginosa were less effective. Ethanolic extracts from $O$. basilicum (F01) was also effective 
on A. niger, S. murinus. Antimicrobial activity of F01 against the $Y$. enterocolitica, $K$. pneumoniae, C. albicans, S. aureus, M. luteus, B. subtilis, $P$. vulgaris and $P$. aureginosa were found to be less effective than the other microorganisms. Diclorometanoic extracts from $O$. basilicum (F02) was also effective on $Y$. enterocolitica, A. niger, S. murinus, S. aureus and $C$. albicans. Antimicrobial activity of F02 against $P$. aeruginosa, $K$. pneumonia, M. luteus, B. subtilis, $P$. vulgaris and $P$. aureginosa were found to be less effective than the other microorganisms. N-Hexanoic extracts from O. basilicum (F03) was also effective on $Y$. enterocolitica, S. murinus, $K$. pneumonia, S. aureus, $C$. albicans and $P$. vulgaris and had inhibition zone with diameters in excess of $38 \mathrm{~mm}$. Antimicrobial activity of the F03 extract against the A. niger, M. luteus, B. subtilis and P. aureginosa were found to be less effective than the other microorganisms. These results were supported by Adigüzel, 2005. Control treatment dimethyl sulfoxide (DMSO) did not show any inhibitory effect on the bacteria (Table $1-2)$.

Essential oil of $T$. spicata (Z00) was very effective on $Y$. enterocolitica, A. niger, $S$. murinus, $K$. pneumonia, $S$, aureus, $M$. luteus, $C$. albicans, $P$. vulgaris, $P$. aeruginosa. The less antimicrobial activity of Z00 against the $B$. subtilis was observed. Moreover, ethanolic extracts from $T$. spicata (Z01) was also very effective on $Y$. enterocolitica, A. niger, $S$. murinus, $K$. pneumonia, $S$, aureus, $M$. luteus, $C$. albicans, $P$. vulgaris, $P$. aeruginosa. Moreover, the less antimicrobial activity of Z01 against the $B$. subtilis was also observed. Diclorometanoic extracts from T. spicata (Z02) was strongly effective on $Y$. enterocolitica, A. niger, S. murinus, $K$. pneumonia, $S$, aureus, $C$. albicans, $P$. vulgaris, $P$. aeruginosa and the less antimicrobial activity of the Z02 against the $M$. luteus, B. subtilis was observed. N- Hexanoic extracts from $T$. spicata (Z03) was strongly effective on $Y$. enterocolitica, A. niger $S$. murinus, $K$. pneumonia, $S$, aureus, $M$. luteus, $P$. aureginosa. Antimicrobial activity of $\mathrm{Z03}$ extract against the $B$. subtilis, $P$. vulgaris, C. albicans was also less effective. Z00 on M. luteus and S.murinus had inhibition zone with diameters in excess of 36 and $30 \mathrm{~mm}$, respectively. Z03 exhibited stronger antimicrobial activity against the microorganisms than those of extracts (43 $\mathrm{mm}$ in diameter). Generally, weaker activity was observed against Gram- negative ones (Table 1-2).

Table 1. Results of antimicrobial screening of $O$. basilicum and $T$. spicata extracts determined by the agar diffusion method (inhibition zone in $\mathrm{mm}$ )

\begin{tabular}{|c|c|c|c|c|c|c|c|c|c|c|}
\hline $\begin{array}{l}\text { Nest } \\
\text { extracts } \\
\mathrm{mg} / \mathrm{ml}\end{array}$ & Y.e. & A.n. & S.m. & K.p. & S.a & M.1. & C.a. & B.s. & P.v. & P.a. \\
\hline $\begin{array}{l}\text { F00 30 } \mu \mathrm{L} \\
(3 \mathrm{mg})\end{array}$ & $17,17,16$ & $23,23,22$ & $35,34,34$ & $11,12,13$ & $14,13,14$ & $11,12,11$ & $10,11,11$ & $19,19,18$ & $30,30,32$ & $14,14,13$ \\
\hline $\begin{array}{l}\text { F01 30 } \mu \mathrm{L} \\
(3 \mathrm{mg})\end{array}$ & $14,14,13$ & $18,18,19$ & $25,24,25$ & $18,17,18$ & $13,12,13$ & $11,10,10$ & $14,13,13$ & $19,19,18$ & $19,19,20$ & $11,12,11$ \\
\hline $\begin{array}{l}\text { F02 30 } \mu \mathrm{L} \\
(3 \mathrm{mg})\end{array}$ & $26,25,26$ & $22,23,22$ & $30,29,29$ & $14,15,15$ & $28,28,27$ & $23,22,22$ & $35,35,34$ & $27,27,26$ & $23,22,22$ & $15,15,16$ \\
\hline $\begin{array}{l}\text { F03 30 } \mu \mathrm{L} \\
(3 \mathrm{mg})\end{array}$ & $38,37,37$ & $18,17,18$ & $36,34,34$ & $33,34,32$ & $32,32,30$ & $30,30,30$ & $30,30,29$ & $28,28,27$ & $30,29,30$ & $20,20,20$ \\
\hline $\begin{array}{l}\mathrm{Z} 0030 \mu \mathrm{L} \\
(3 \mathrm{mg})\end{array}$ & $23,23,24$ & $29,29,28$ & $30,32,30$ & $22,23,22$ & $30,32,30$ & $36,36,35$ & $30,29,29$ & $29,29,30$ & $32,32,32$ & $27,27,26$ \\
\hline $\begin{array}{l}\mathrm{Z} 0130 \mu \mathrm{L} \\
(3 \mathrm{mg})\end{array}$ & $24,24,23$ & $33,34,33$ & $32,32,30$ & $22,22,21$ & $33,34,33$ & $35,35,36$ & $30,30,32$ & $30,32,30$ & $30,29,29$ & $33,34,33$ \\
\hline $\begin{array}{l}\mathrm{Z} 0230 \mu \mathrm{L} \\
(3 \mathrm{mg})\end{array}$ & $25,24,25$ & $27,27,28$ & $32,33,30$ & $22,23,21$ & $33,34,33$ & $30,32,30$ & $35,36,36$ & $32,32,30$ & $20,19,20$ & $27,26,26$ \\
\hline $\begin{array}{l}\mathrm{Z} 0330 \mu \mathrm{L} \\
(3 \mathrm{mg})\end{array}$ & $21,21,20$ & $28,28,27$ & $32,33,33$ & $21,21,22$ & $30,29,29$ & $43,43,42$ & $16,16,17$ & $21,22,21$ & $22,21,22$ & $29,28,28$ \\
\hline Solvent & $6,6,6$ & $6,6,6$ & $6,6,6$ & $6,6,6$ & $6,6,6$ & $6,6,6$ & $6,6,6$ & $6,6,6$ & $6,6,6$ & $6,6,6$ \\
\hline Ampicillin & $20,21,21$ & NT & $20,22,23$ & $22,23,22$ & $24,24,23$ & $6.00 \pm 0.00$ & NT & $38,39,40$ & $30,30,32$ & $29,30,32$ \\
\hline Cefazolin & $20,21,22$ & NT & 6.6.6. & $22,23,23$ & $22,22,23$ & $36,38,38$ & NT & $38,36,35$ & 6.6 .6 & $26,27,27$ \\
\hline Nystain & NT & $18,19,19$ & NT & NT & NT & NT & $20,21,21$ & NT & NT & NT \\
\hline
\end{tabular}

F00: Essential oil of $O$. basilicum, F01: Ethanolic extract of $O$. basilicum, F02: Dicloromethanoic extract of $O$. basilicum, F03: n- hexanoic extract of O. basilicum, Z0: Essential oil of T. spicata, Z01: Ethanolic extracts of $T$. spicata, Z02: Dicloromethanoic extract of T. spicata, Z03: n-hexanoic extract of T. Spicata, Y.e.: Y. enterocolitica, A.n.: A. niger, S.m.: S. murinus, K.p.: K. pneumoniae, S.a.: S. aureus, M.1.: M. luteus, C.a.: C. albicans, B.s.: B. subtilis, P.v.: P. vulgaris, P.a.: P. aeruginosa, NT: Not tested. 
Table 2. Results of antimicrobial screening of $O$. basilicum and $T$. spicata of essential oils and (DMSO) extracts determined by the well diffusion method (minimum inhibitory concentration in $\mathrm{mg} / \mathrm{ml}$ )

\begin{tabular}{lcccccccccc}
\hline $\begin{array}{l}\text { Nest } \\
\text { extracts }\end{array}$ & Y.e. & A.n. & S.m. & K.p. & S.a & M.1. & C.a. & B.s. & P.v. & P.a. \\
mg/ml & & & & & & & & & & \\
\hline F00 & $0.5 \leq$ & $0.5 \leq$ & $0.25 \leq$ & $1 \leq$ & $1 \leq$ & $1 \leq$ & $1 \leq$ & $0.5 \leq$ & $0.25 \leq$ & $1 \leq$ \\
F01 & $0.5 \leq$ & $0.25 \leq$ & $0.25 \leq$ & $0.5 \leq$ & $1 \leq$ & $1 \leq$ & $1 \leq$ & $0.5 \leq$ & $0.5 \leq$ & $0.5 \leq$ \\
F02 & $0.25 \leq$ & $0.5 \leq$ & $0.25 \leq$ & $0.5 \leq$ & $0.5 \leq$ & $0.5 \leq$ & $0.25 \leq$ & $0.25 \leq$ & $0.5 \leq$ & $0.5 \leq$ \\
F03 & $0.25 \leq$ & $0.5 \leq$ & $0.25 \leq$ & $0.25 \leq$ & $0.25 \leq$ & $0.25 \leq$ & $0.25 \leq$ & $0.25 \leq$ & $0.25 \leq$ & $0.5 \leq$ \\
Z00 & $0.25 \leq$ & $0.25 \leq$ & $0.25 \leq$ & $0.5 \leq$ & $0.25 \leq$ & $0.25 \leq$ & $0.25 \leq$ & $0.25 \leq$ & $0.25 \leq$ & $0.25 \leq$ \\
Z01 & $0.5 \leq$ & $0.25 \leq$ & $0.25 \leq$ & $0.5 \leq$ & $0.25 \leq$ & $0.25 \leq$ & $0.25 \leq$ & $0.25 \leq$ & $0.25 \leq$ & $0.25 \leq$ \\
Z02 & $0.5 \leq$ & $0.25 \leq$ & $0.25 \leq$ & $0.25 \leq$ & $0.25 \leq$ & $0.25 \leq$ & $0.25 \leq$ & $0.25 \leq$ & $0.5 \leq$ & $0.25 \leq$ \\
Z03 & $0.5 \leq$ & $0.25 \leq$ & $0.25 \leq$ & $0.5 \leq$ & $0.25 \leq$ & $0.25 \leq$ & $0.5 \leq$ & $0.25 \leq$ & $0.25 \leq$ & $0.25 \leq$ \\
\hline
\end{tabular}

F00: Essential oil of O. basilicum, F01: Ethanolic extract of O. basilicum, F02: Dicloromethanoic extract of O. basilicum, F03: $n$ - hexanoic extract of O. basilicum, Z0: Essential oil of T. spicata, Z01: Ethanolic extracts of T. spicata, Z02: Dicloromethanoic extract of T. spicata, Z03: $n$-hexanoic extract of T. Spicata, Y.e.: Y. enterocolitica, A.n.: A. niger, S.m.: S. murinus, K.p.: K. pneumoniae, S.a.: S. aureus, M.l.: M. luteus, C.a.: C. albicans, B.s.: B. subtilis, P.v.: P. vulgaris, P.a.: P. aeruginosa, NT: Not tested.

It was observed in present study that essential oil and the extracts of $T$. spicata have the most effective and significant activity against the bacteria, yeast and mold. In addition, Z01 have more effective than the other extracts. This mean that extract of polar solvents is more effective than the extract of apolar solvents on the microorganisms.

There were a lot of reports on the antimicrobial activity of the essential oil of Lamiaceae. Although our study showed that essential oil and extract of Lamiaceae exhibited antimicrobial activity against all test microorganisms, these works of literature are concerned and weak antimicrobial activity was observed against microorganisms including $S$. aureus and $P$. aeruginosa [24, 25].

\subsection{Antioxidant Activity}

The present study was carried out in order to evaluate the in vitro antioxidant potential and phenolic compounds of $T$. spicata and $O$. basilicum plants. In total four complementary test systems were used in the assessment including total phenolic, flavonoid and condensed tannin contents. Total phenolic contents values by themselves may not be sufficiently in order to draw any definitive conclusions regarding the antioxidant potential of biological samples [26]. Therefore, some additional assays, such as FRAP concentration determinations were used throughout this study.

The total amount of phenolic, flavonoid and tannin content present in methanolic $O$. basilicum and T. spicata extract is shown Table 3. It was found that $100 \mathrm{~g}$ of $O$. basilicum and T. spicata, 731.22 to $969.53 \mathrm{GAE}$ of phenols, 0.12 to $0.14 \mathrm{mg} \mathrm{QE}$ of flavonoid and 335.72 to $646.49 \mathrm{mg}$ CE of tannin were detected respectively. In addition, it was found that $100 \mathrm{~g}$ of $O$. basilicum and T. spicata, extract 11.884 to 15.106 of FRAP $\mu \mathrm{mol}$ Trolox. These results indicated that antioxidant activity of the T. spicata was higher than that of the O. basilicum.

Table 3. Antioxidant parametres of $O$. basilicum and T. spicata

\begin{tabular}{|c|c|c|c|c|}
\hline Samples & $\begin{array}{c}\text { TP (mg } \\
\text { GAE/100g } \\
\text { sample) }\end{array}$ & $\begin{array}{l}\text { TF (mg } \\
\text { QE/100g } \\
\text { sample) }\end{array}$ & $\begin{array}{l}\text { CT (mg } \\
\text { CE/100g } \\
\text { sample) }\end{array}$ & $\begin{array}{c}\text { FRAP } \\
(\mu \text { molTrolox } / 100 \mathrm{~g} \\
\text { sample })\end{array}$ \\
\hline Ocimum basilicum & $731.22 \pm 6.250$ & $0.12 \pm 0.001$ & $335.72 \pm 0.001$ & $11.884 \pm 0.357$ \\
\hline Thymbra spicata & $969.53 \pm 10.501$ & $0.14 \pm 0.001$ & $646.49 \pm 116.00$ & $15.106 \pm 0.180$ \\
\hline
\end{tabular}


Fourteen phenolic compounds were analysed and some phenolics were detected in O.basilicum and T. spicata (Table 3). $t$-cinnamic acid and vanillic acid were identified as the major phenolic compounds in both plants. In addition to syringic acid was identified in $T$. spicata.

Table 4. Phenolic profiles of the $O$. basilicum and T. spicata

\begin{tabular}{lcc}
\hline Standards & $\begin{array}{c}\text { O. basilicum } \\
(\mu \mathrm{g} \text { phenolic/g sample) }\end{array}$ & $\begin{array}{c}\text { T. spicata } \\
(\mu \mathrm{g} \text { phenolic/g sample) }\end{array}$ \\
\hline Gallic Acid & n.d. & n.d. \\
Protocatequic Acid & 10.557 & 20.578 \\
$p$-OH Benzoic Acid & 40.395 & 17.411 \\
Catechin & n.d. & n.d. \\
Vanillic Acid & 43.375 & 50.198 \\
Caffeic Acid & n.d. & n.d. \\
Syringic Acid & n.d. & 183.246 \\
Epicatechin & n.d. & n.d. \\
$p$-Coumaric Acid & 12.282 & n.d. \\
Ferulic Acid & 8.875 & 28.808 \\
Rutin & 5.501 & 77.042 \\
Daizein & 2.929 & 9.783 \\
$t$-Cinnamic Acid & 58.023 & 545.185 \\
Luteolin & 14.940 & n.d. \\
\hline
\end{tabular}

Phenolic compounds are substances that have redox properties and those properties make them good antioxidants acting as reducing agent, hydrogen donors and singlet oxygen quenchers [27]. Fourteen phenolic compounds were analyzed and some phenolics were detected in $O$. basilicum and $T$. spicata (Table 4). $t$-cinnamic acid and vanillic acid were identified as the major phenolic compounds in both plants. In addition to syringic acid was identified in T. spicata. It was reported that $O$. basilicum with major compounds rutin and two hydroxycinnamic acid derivates, namely ferulic acid and $p$-coumaric acid were identified and quantified that the result similar to our result [28].

\section{CONCLUSION}

In this study antimicrobial effect of various extracts and essential oil of two plants (Lamiaceae family) were carried out. This investigation denotes that essential oil of T. spicata and $\mathrm{O}$. bacilium have significant activity against microorganisms. The essential oil also shows antioxidant activity. In addition, we saw phenolic profile these plants. These results verify the potential use of plant essential oils and extracts in the pharmaceutical industries. Phenolic profile of these plants could be a benefit for treatment microbial diseases.

\section{Conflict of Interests}

Authors declare that there is no conflict of interests.

\section{REFERENCES}

[1]. Robbers, J., Speedie, M., \& Tyler, V. (1996). Pharmacognosy and pharmacobiotechnology. Williams and Wilkins, 1-14.

[2]. Allen, K.L., Molan, P.C., \& Reia, G.M. (1991). A survey of the antibacterial activity of some New Zeland honeys. Journal of Pharmacy and Pharmacology, 43, 817-822.

[3]. Mahasneh, A.M.A., Adel, M.A., \& El-Oqlah, A.A.B. (1999). Antimicrobial activity of extracts of herbal plants used in the traditional medicine of Jordan. Journal of Ethnopharmacology, 64, 271-276. 
[4]. Tada, H., Murakami, Y., \& Omoto T. (1996). Rosmarinic acid and related phenolics in hairy root cultures of Ocimum basilicum. Phytochemistry, 42, 431-434.

[5]. Reuveni, R., Raviv, M., \& Krasnovsky, A. (2002). Compost induces protection against Fusarium oxysporum in sweet basil. Crop Protection, 21, 583-587.

[6]. Baritaux, O., Richard, H., Touche, J., \& Derbesy, M. (1992). Effects of drying and storage of herbs and spices on the essential oil. Part I. Basil, Ocimum basilicum L. Flavour Fragrance Journal, 7, 267-271.

[7]. Lahariya, A. K., \& Rao, J.T. (1979). In vitro antimicrobial studies of the essential oil of Cyperus scariosus and Ocimum basilicum. Indian Drugs Journal, 16, 150-152.

[8]. Dube, S., Upadhyay, P.D., \& Tripathi, S.C. (1989). Antioxidant, physicochemical and insect-repelling activity of the essential oil of Ocimum basilicum. Canadian Journal of Botany, 67, 2085-2087.

[9]. Özcan, M. (1998). Inhibitory effects of spice extracts on the growth of Aspergillus parasiticus NRRL 2999 strain. Zeitschrift für Lebensmitteluntersuchung und Forschung A, 207, 253-255.

[10]. Baytop, T. (1997). A dictionary of vernacular names of wild plants of Turkey, Istanbul.

[11]. Baytop, T. (Ed.) (1999). Türkiye'de bitkiler ile tedavi (treatment with plants in Turkey), Istanbul.

[12]. Baser, K.H.C. (1993). Essential oils of Anatolian Labiatae: A profile. Acta Horticulture, 333, 217-238.

[13]. Farag, R.S., Daw, Z.Y., Hewedi, F.M., \& El-Baroty, G.S.A. (1989). Antimicrobial activityof some Egyptian spice essential oils. Journal of Food Protection, 52, 665-667.

[14]. Bozin, B., Mimica-Dukic, N., Simin, N., \& Anackov, G. (2006). Characterization of the volatile composition of essential oil of some Lamiaceae species and the antimicrobial and antioxidant activities of the entire oils. Journal of Agriculture and Food Chemistry, 54, 1822- 1828.

[15]. Adıgüzel, A., Güllüce, M., Şengül, M., Ögütücü, H., Şahin, F., \& Karaman, İ. (2005) Antimicrobial effect of Ocimum bacilicum (Lamiateae) extract. Turkish Journal of Biology, 29, 155-160.

[16]. Hammer, K.A., Carson, C.F., \& Riley, T.V. (1999). Antimicrobial activity of essential oils and other plant extracts. Journal of Applied Microbiology, 86, 985-990.

[17]. Ronald M.A. (1990). Microbiologia compania editorial continental S.A. de C.B., Mexico, DF.

[18]. Vander, B.D.A., \& Vietinck, A.J. (1991). Screening methods for antimicrobial and antiviral agents from higger plants, London.

[19]. Singleton, V.L., \& Rossi, J.L. (1965). Colorimetry of total phenolics with phosphomolybdic-phosphotungstic acid reagents. American Society of Enology and Viticulture, 16, 144-158.

[20]. Fukumoto, L.R., \& Mazza, G. (2000). Assessing antioxidant and prooxidant activities of phenolic compounds. Journal of Agricultural Food Chemistry, 48, 3597-3604.

[21]. Julkunen-Titto, R. (1985). Phenolic constituents in the leaves of northernwillows: methods for the analysis of certain phenolics. Journal of Agricultural Food Chemistry, 33, 213-217.

[22]. Benzie, I.F.F., \& Strain, J.J. (1999). Ferric reducing/antioxidant power assay: Direct measure of total antioxidant activity of biological fluids and modified version for simultaneous measurement of total antioxidant power and ascorbic acid concentration. In Methods in Enzymology, 299, 15-27. 
[23]. Can, Z., Yildiz, O., Şahin, H., Turumtay, E.A., Silici, S., \& Kolayli, S. (2015). An investigation of Turkish honeys: their physicochemical properties, antioxidant capacites and phenolic profiles. Food Chemistry, 180, 133-141.

[24]. Haznedaroglu, M. Z., Karabay, U., \& Zeybek, U. (2001). Antimicrobial activity of Salvia tomentosa essential oil. Fitoterapia, 72, 829-831.

[25]. Tepe, B., Daferera, D., Sokmen, A., Sokmen, M., \& Polissiou, M. (2005). Antimicrobial and antioxidant activities of the essential oil and various extracts of Salvia tomentosa (Lamiaceae). Food Chemistry, 90, 333-340.

[26]. Sahin, H., Akyuz-Turumtay, E., Yildiz, O., \& Kolayli, S. (2015). Grayanotoxin-III detection and antioxidant activity of mad honey. International Journal of Food Properties, 18(12), 2665-2674.

[27]. Djeridane, A., Yousfi, M., Nadjemi, B., Boutassouna, D., Stocker, P., \& Vidal, N. (2006). Antioxidant activity of some Algerian medicinal plants extracts containing phenolic compounds. Food Chemistry, 97, 654-660.

[28]. Vlase, L., Benedec, D., Hanganu, D., Damian, G., \& Csillag, I. (2014). Evaluation of antioxidant and antimicrobial activities and phenolic profile for Hyssopus officinalis, Ocimum basilicum and Teucrium chamaedrys. Molecules, 19, 5490-5507. 